\title{
Temperature-Dependent Electrochemical Characteristics of Antimony Nanocrystal Alloying Electrodes for Na-Ion Batteries
}

\section{Supporting Information}

Authors: Grant A. Williamson, ${ }^{\dagger}$ Victor W. Hu, ${ }^{\ddagger}$ Thomas B. Yoo,${ }^{\ddagger}$ Martin Affandy, ${ }^{\ddagger}$ Charles Opie, ${ }^{\ddagger}$ Emilee K. Paradis, ${ }^{\#}$ and Vincent C. Holmberg $*, \dagger, \ddagger \S$

\section{Affiliations:}

${ }^{\dagger}$ Molecular Engineering \& Sciences Institute, University of Washington, Seattle, Washington 98195-1652, United States

Department of Chemical Engineering, University of Washington, Seattle, Washington 981951750, United States

${ }^{\S}$ Clean Energy Institute, University of Washington, Seattle, Washington 98195-1653, United States

\#Pierce College Puyallup, Puyallup, Washington 98374, United States

*Correspondence to holmvc@uw.edu

\section{Ambient Temperature Effects on Capacity}

Long-term cycling data showing the variations in capacity for an antimony nanocrystal composite electrode being cycled in a laboratory environment without temperature control, along with the corresponding ambient temperatures recorded at Seattle-Tacoma International airport, which is approximately 15 miles from the University of Washington lab where the battery was tested are

pictured in Figure S1. Battery testing was carried out during a period where large day-night temperature swings $\left(\sim 20^{\circ} \mathrm{C}\right)$ occurred, which resulted in large temperature-correlated oscillations in the recorded electrode capacity. Clearly, these observations indicate that developing a detailed 
understanding of the temperature-dependence of antimony nanocrystal composite electrodes is critical for their potential implementation in real-world energy-intensive, high-power applications.

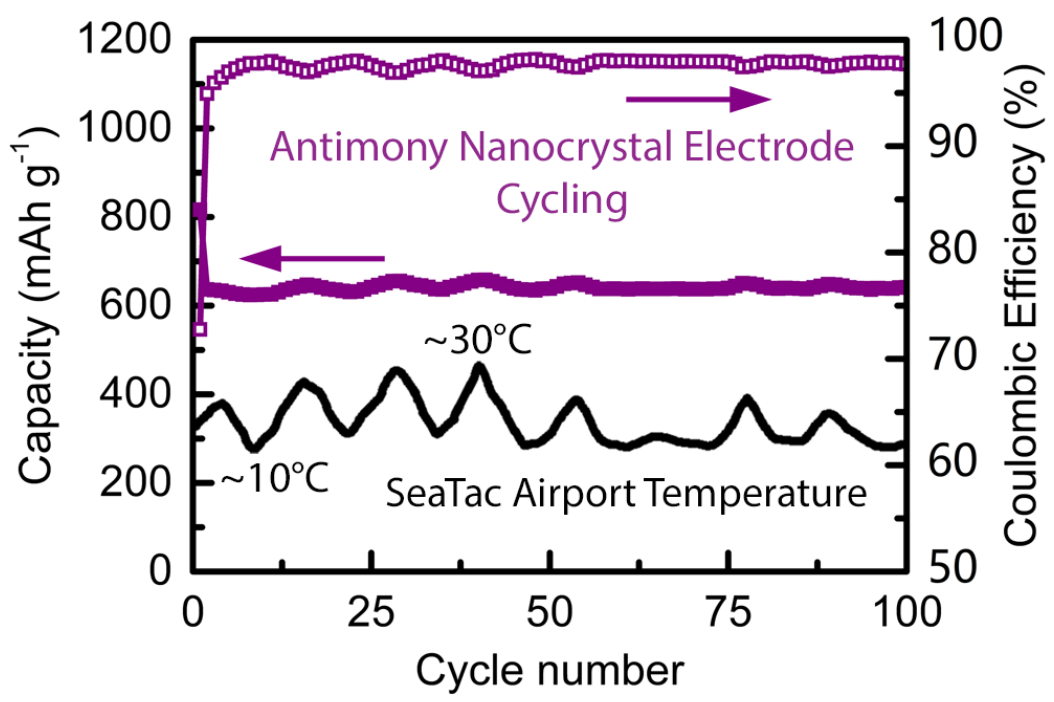

Figure S1. Variations in capacity and Coulombic efficiency for antimony nanocrystal conversion electrodes cycled in a lab without temperature control, correlated with the recorded temperature variations measured at Seattle Tacoma International Airport over the cycling period from May 25, 2017 through June 2, $2017 .^{1}$

\section{Antimony Nanocrystal Characterization}

Antimony nanocrystals were synthesized via a modified version of the procedure developed by Walter et al. (Figure S2). ${ }^{2}$ The macroscale product consists of aggregated nanocrystals of rhombohedral (R $\overline{3} \mathrm{~m})$ antimony (PDF \#00-035-0732) with an average diameter of $\sim 40 \mathrm{~nm}$ based on a Rietveld refinement of the XRD data (Figure S2c). Notably, while highly monodisperse antimony nanocrystal syntheses have also been developed, ${ }^{3}$ the procedure of Walter et al. enables low-cost, large-scale nanocrystal production with much higher product yields. While the resulting nanocrystal product tends to be less monodisperse and more aggregated than small- 
scale precision syntheses, the electrochemical cycling characteristics remain equivalent, cycling reversibly with no significant change in Na-ion battery performance for nanocrystals with diameters between 20 and $100 \mathrm{~nm} .^{2,3}$

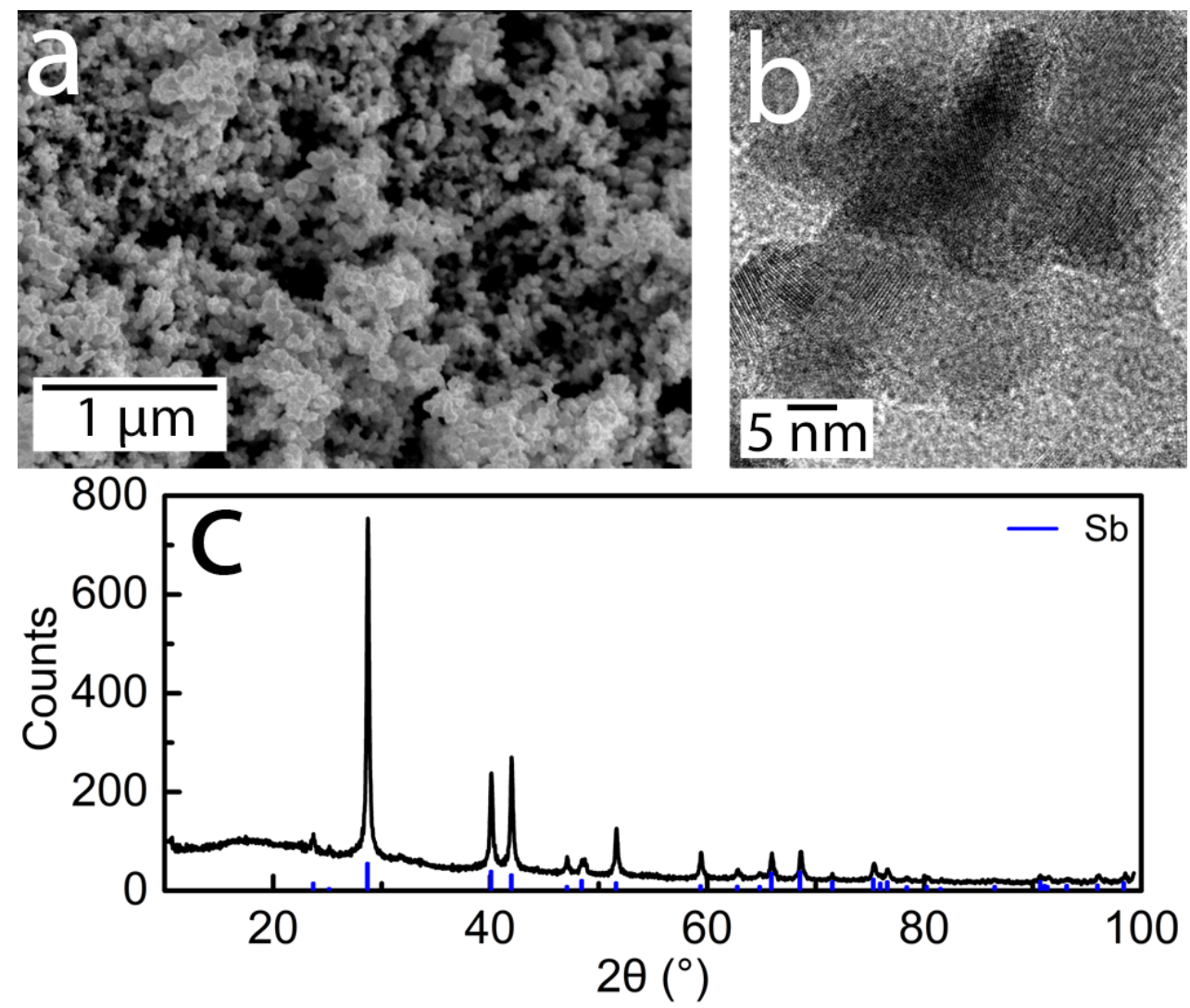

Figure S2. a) Scanning electron microscopy (SEM), b) transmission electron microscopy (TEM), and c) X-ray diffraction (XRD) of the as-synthesized antimony nanocrystal active material.

\section{Electrode Morphology}

The antimony nanocrystal-based electrodes exhibit an increased degree of SEI layer formation as the cycling temperature is increased (Figure S3). The increased SEI layer formation is substantially more pronounced at $50^{\circ} \mathrm{C}$ than at $5^{\circ} \mathrm{C}$ and $20^{\circ} \mathrm{C}$, particularly when compared to the uncycled electrode. At high temperatures, increased SEI layer formation is favored because more thermal energy is available to drive the side reactions that result in SEI layer formation. ${ }^{4}$ The 
observed build-up of the SEI layer at $50^{\circ} \mathrm{C}$ also indicates that SEI layer formation is more favored than the reverse SEI layer dissolution reaction, thus resulting in a lowered coulombic efficiency at $50^{\circ} \mathrm{C}$, because a significant fraction of the increased SEI layer formation consists of irreversible reactions that only provide capacity during sodiation (Figure 1a). Nonetheless, within the parameter space investigated, this increased SEI layer formation does not outweigh the temperature-driven reduction in impedances that leads to increased capacity.
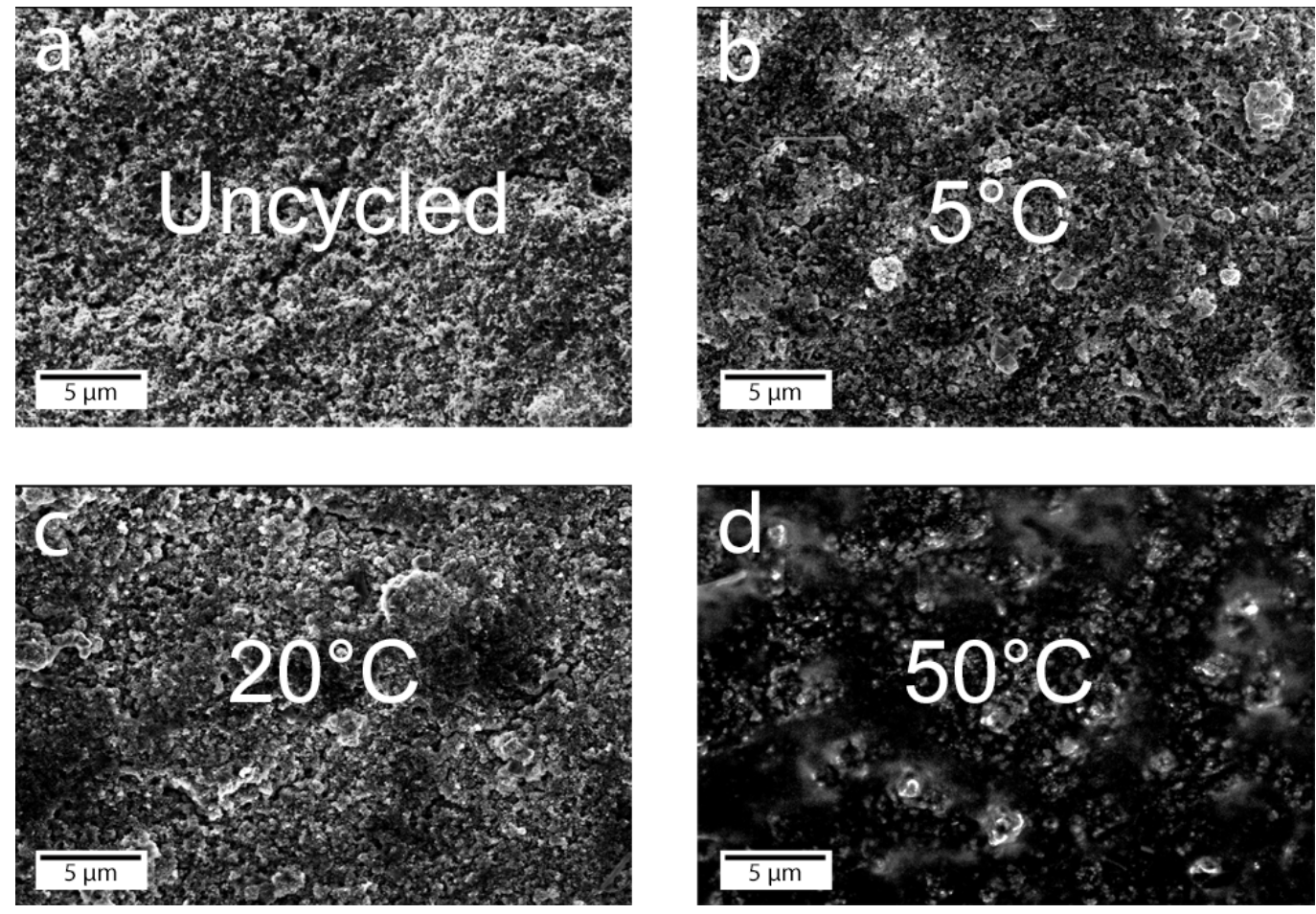

Figure S3. Postmortem SEM images of antimony nanocrystal-based electrodes a) before cycling, and (b-d) after cycling at b) $5^{\circ} \mathrm{C}$, c) $20^{\circ} \mathrm{C}$, and d) $50^{\circ} \mathrm{C}$ for 10 cycles at a rate of $1 \mathrm{C}$.

\section{Temperature-Dependent EIS Data}

The temperature-dependent EIS data for electrodes cycled at $5^{\circ} \mathrm{C}, 35^{\circ} \mathrm{C}$, and $50^{\circ} \mathrm{C}$ are shown in Figure S4 below, varying monotonically across the voltage range investigated, as seen for the room-temperature $20^{\circ} \mathrm{C}$ measurements (Figure 2). 

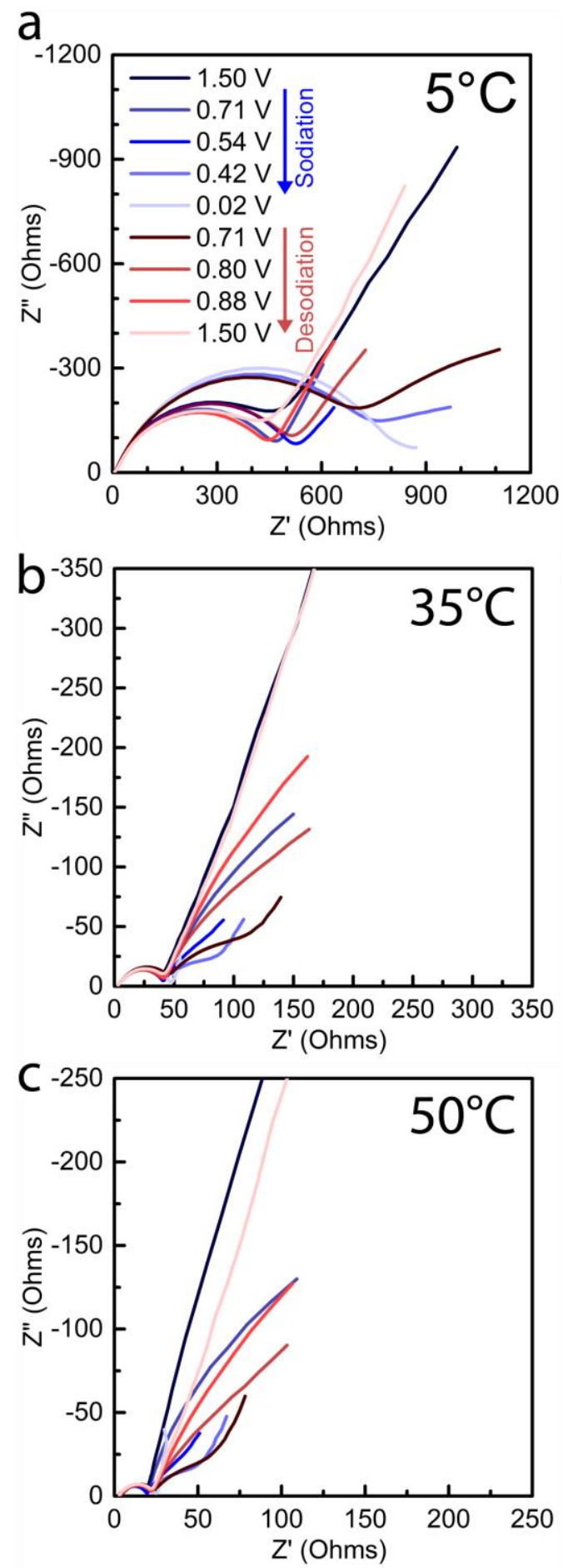

Figure S4. Temperature-dependent Nyquist plots collected over a frequency range spanning from $0.1 \mathrm{~Hz}$ to $100,000 \mathrm{~Hz}$ at (a) $5^{\circ} \mathrm{C}$, (b) $35^{\circ} \mathrm{C}$, and (c) $50^{\circ} \mathrm{C}$ for the terminal sodiation states at $0.02 \mathrm{~V}$ and $1.5 \mathrm{~V}$, and several intermediate potentials $(0.42 \mathrm{~V}, 0.54 \mathrm{~V}$, and $0.71 \mathrm{~V}$ for sodiation and 0.71 $\mathrm{V}, 0.80 \mathrm{~V}$, and $0.88 \mathrm{~V}$ for desodiation). 


\section{Chemical Capacitance}

The real component of the capacitance can indicate whether the chemical capacitance - an equivalent circuit in EIS fitting that accounts for the charging ability of the electrode - is a significant component of the system. In cases where the chemical capacitance is a significant contributor to the overall capacitive response of the system, the real component of the capacitance will show two plateaus when plotted versus frequency on a logarithmic scale. ${ }^{5}$ The plateau at high frequency is indicative of the double-layer capacitance and the plateau at low frequency is indicative of the chemical capacitance. As seen in Figure S5, the plateau at low frequency is only observed at $35^{\circ} \mathrm{C}$ and $50^{\circ} \mathrm{C}$ for the $1.5 \mathrm{~V}$ data and does not occur at all for the $0.02 \mathrm{~V}$ data. This demonstrates that, within the testing regime, the presence of the chemical capacitance is both temperature and voltage dependent. Due to a lack of observed characteristics associated with the chemical capacitance at low temperature and at $0.02 \mathrm{~V}$, chemical capacitance was not used for EIS fitting. 

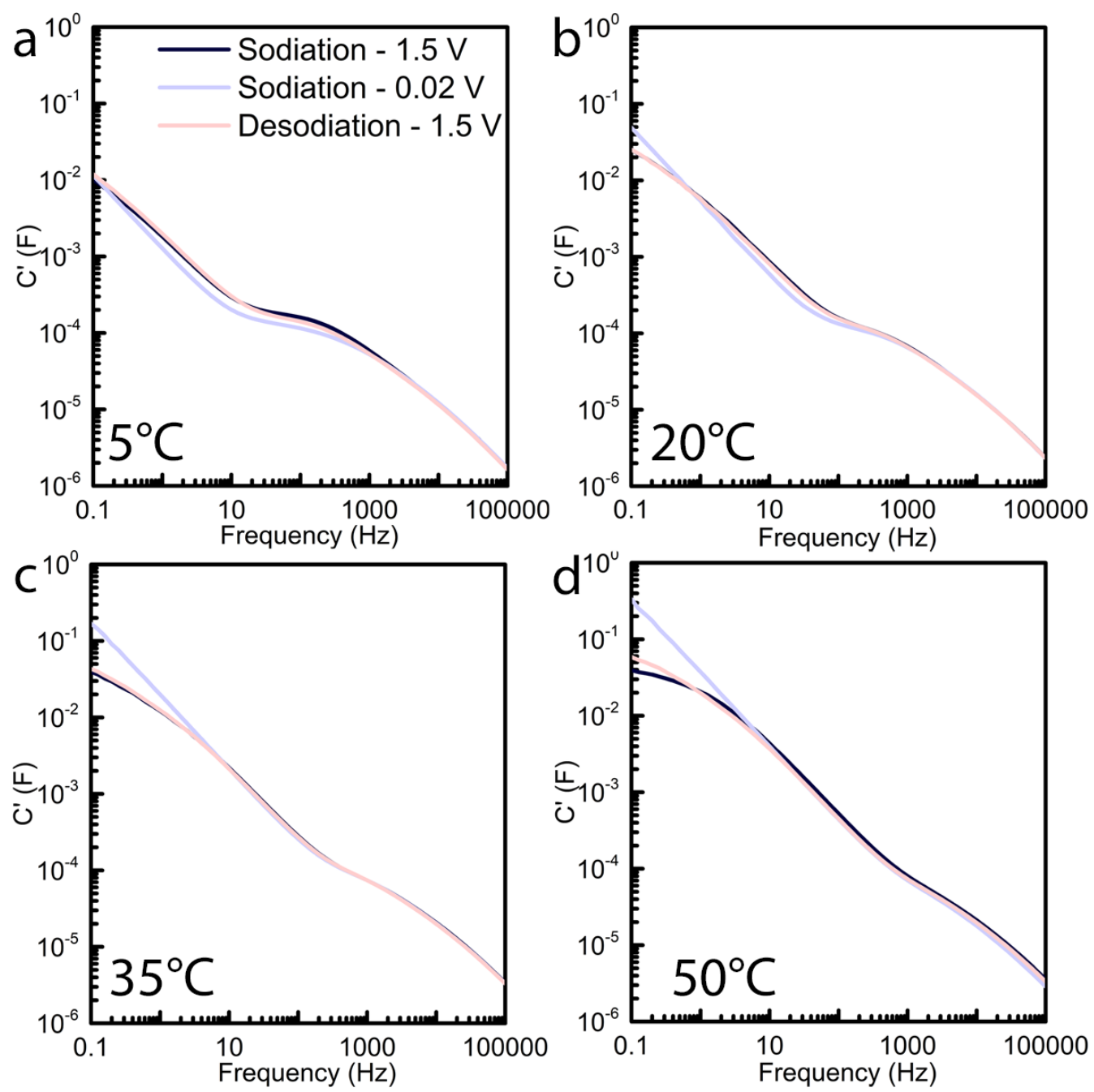

Figure S5. Temperature-dependent capacitance plots collected over a frequency range spanning from $0.1 \mathrm{~Hz}$ to $100,000 \mathrm{~Hz}$ at (a) $5^{\circ} \mathrm{C}$, (b) $20^{\circ} \mathrm{C}$, (c) $35^{\circ} \mathrm{C}$, and (d) $50^{\circ} \mathrm{C}$ for the terminal sodiation states at $0.02 \mathrm{~V}$ and $1.5 \mathrm{~V}$

\section{EIS Fitting Data}

The $R_{\text {cell }}, R_{c t}$, and $C P E_{W, T}$ parameters from the EIS fits of the $1.5 \mathrm{~V}$ and $0.02 \mathrm{~V}$ spectra at $5^{\circ} \mathrm{C}$, $20^{\circ} \mathrm{C}, 35^{\circ} \mathrm{C}$, and $50^{\circ} \mathrm{C}$ exhibit monotonic trends with temperature, indicating that these parameters are correlated with the temperature-dependent capacity of the antimony nanocrystal composite electrodes (Figure S6, Tables S1-S3). The $C P E_{d l, T}, C P E_{d l, P}$, and $C P E_{W, P}$ parameters do not 
respond monotonically with temperature at either $1.5 \mathrm{~V}$ and $0.02 \mathrm{~V}$, indicating that these parameters do not drive the temperature-dependence of the capacity (Figure S6, Tables S1-S3). The characteristics of the $R_{c e l l}, R_{c t}$, and $C P E_{W, T}$ parameters for the $1.5 \mathrm{~V}$ state of charge after desodiation are discussed in detail in the main manuscript. The $R_{c e l l}$ and $R_{c t}$ parameters at the 1.5 $\mathrm{V}$ state of charge before sodiation and at the $0.02 \mathrm{~V}$ state of charge after sodiation both have very similar values to the $R_{c e l l}$ and $R_{c t}$ parameters at the $1.5 \mathrm{~V}$ state of charge after desodiation, with the exception of the $R_{c t}$ parameter value for the $0.02 \mathrm{~V}$ state of charge after sodiation at $5^{\circ} \mathrm{C}(550$ $\Omega$ at the $1.5 \mathrm{~V}$ state of charge after desodiation $v s .865 \Omega$ at the $0.02 \mathrm{~V}$ state of charge after sodiation). This difference indicates that charge transfer at low temperatures is more difficult at high states of charge than at low states of charge. However, as temperature is increased, this difference in charge transfer resistance at high states of charge and at low states of charge lessens. The $C P E_{W, T}$ parameter has very similar values for both the $1.5 \mathrm{~V}$ state of charge before sodiation and the $1.5 \mathrm{~V}$ state of charge after desodiation, indicating that the degradation in cell performance due to this parameter was small during EIS testing. The $C P E_{W, T}$ parameter is larger for the fully sodiated state at $0.02 \mathrm{~V}$ after sodiation than for the fully desodiated state at $1.5 \mathrm{~V}$. The diffusion coefficient has been calculated in the literature within the region from $0.1 \mathrm{~V}$ to $0.7 \mathrm{~V}$, and within this region, the diffusion coefficient continuously declines in value as voltage is increased. ${ }^{6}$ Assuming that this trend continues across the voltage window, this would match the observed changes in the $C P E_{W, T}$ parameter, given that $C P E_{W, T}$ and the diffusion constant are directly proportional. 

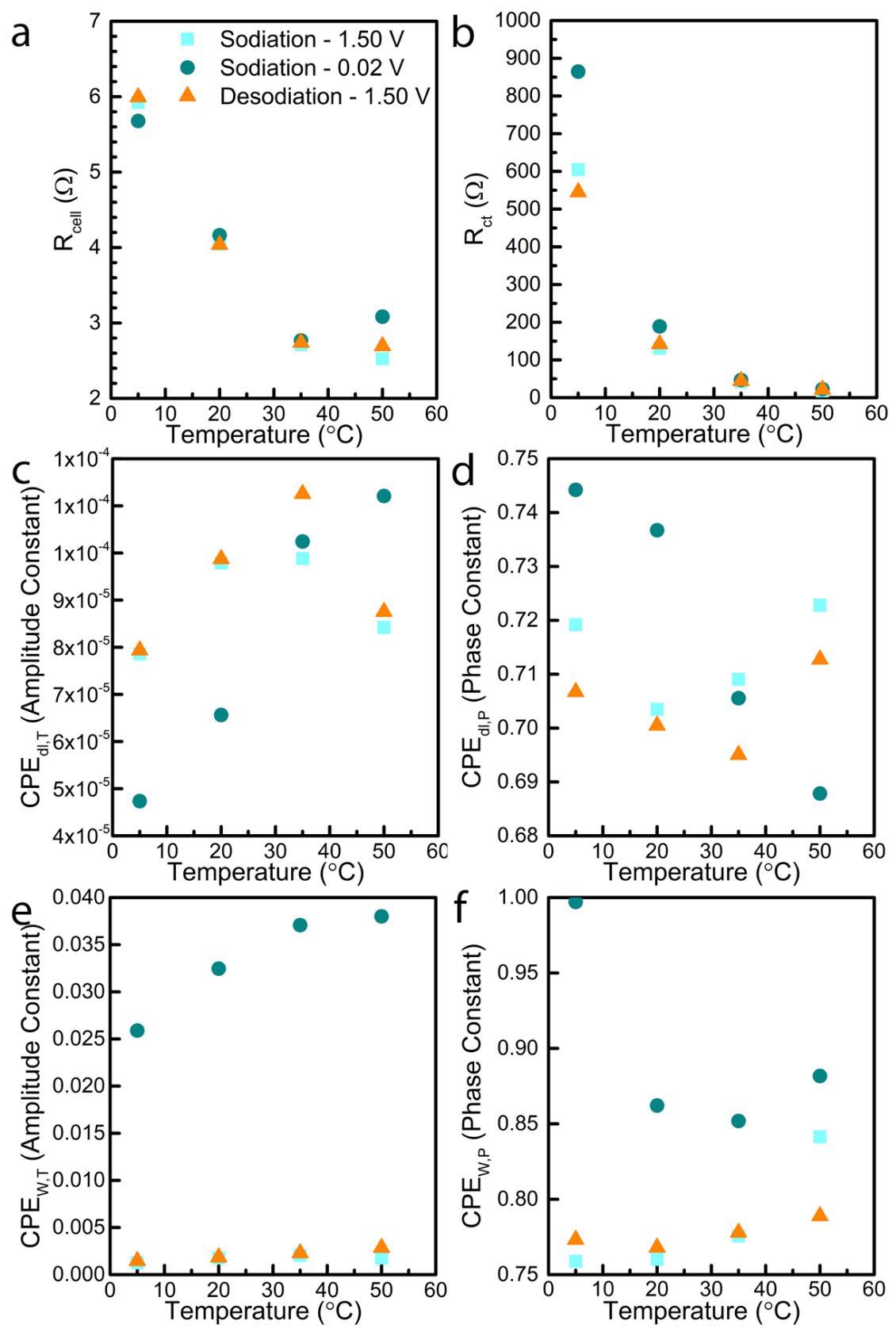

Figure S6. Model fit parameters as a function of temperature for (a) cell resistance, (b) charge transfer resistance, (c) amplitude constant for the constant phase element associated with the double-layer capacitance, (d) phase constant for the constant phase element associated with the double-layer capacitance, (e) amplitude constant for the constant phase element associated with the Warburg diffusion element, and (f) phase constant for the constant phase element associated with the Warburg diffusion element. 
Table S1. Model fit parameters and associated error bounds for a $1.5 \mathrm{~V}$ state of charge before sodiation.

\begin{tabular}{|c|c|c|c|c|}
\hline & $5^{\circ} \mathbf{C}$ & $20^{\circ} \mathrm{C}$ & $35^{\circ} \mathrm{C}$ & $5^{\circ} \mathrm{C}$ \\
\hline $\mathbf{R}_{\text {cell }}(\Omega)$ & $5.9 \pm 0.1$ & $4.05 \pm 0.06$ & $2.71 \pm 0.03$ & $2.53 \pm 0.03$ \\
\hline \multirow{2}{*}{$\begin{array}{c}\text { CPE }_{d l, T} \\
\left(\mathbf{s}^{\mathrm{CPEdl}, \mathbf{P} / \Omega)}\right.\end{array}$} & $(7.9 \pm 0.3)$ & $(9.8 \pm 0.4)$ & $(9.9 \pm 0.4)$ & $(8.4 \pm 0.4)$ \\
\hline & $\times 10^{-5}$ & $\times 10^{-5}$ & $\times 10^{-5}$ & $\mathrm{x} 10^{-5}$ \\
\hline $\begin{array}{c}\text { CPE }_{d l, P} \text { (Phase } \\
\text { Constant) }\end{array}$ & $0.719 \pm 0.006$ & $0.703 \pm 0.005$ & $0.709 \pm 0.005$ & $0.723 \pm 0.005$ \\
\hline $\mathbf{R}_{\text {ct }}(\boldsymbol{\Omega})$ & $610 \pm 20$ & $130 \pm 2$ & $41.9 \pm 0.4$ & $17.9 \pm 0.1$ \\
\hline \multirow{2}{*}{$\begin{array}{c}\text { CPEW,T } \\
\left(\mathbf{s}^{\mathrm{CPEW}, \mathbf{P} / \Omega)}\right.\end{array}$} & $(1.25 \pm 0.04)$ & $(1.76 \pm 0.02)$ & $(2.05 \pm 0.01)$ & $(1.76 \pm 0.01)$ \\
\hline & x $10^{-3}$ & $\mathrm{x} 10^{-3}$ & $\mathrm{x} 10^{-3}$ & $\mathrm{x} 10^{-3}$ \\
\hline $\begin{array}{c}\text { CPEw,P (Phase } \\
\text { Constant) }\end{array}$ & $0.76 \pm 0.02$ & $0.760 \pm 0.007$ & $0.776 \pm 0.003$ & $0.841 \pm 0.002$ \\
\hline$\chi^{2}$ & 0.006 & 0.002 & 0.0009 & 0.0007 \\
\hline
\end{tabular}


Table S2. Model fit parameters and associated error bounds for a $0.02 \mathrm{~V}$ state of charge after sodiation.

\begin{tabular}{|c|c|c|c|c|}
\hline & $5^{\circ} \mathrm{C}$ & $20^{\circ} \mathrm{C}$ & $35^{\circ} \mathrm{C}$ & $50^{\circ} \mathrm{C}$ \\
\hline $\mathbf{R}_{\text {cell }}(\boldsymbol{\Omega})$ & $5.68 \pm 0.06$ & $4.16 \pm 0.05$ & $2.77 \pm 0.03$ & $3.08 \pm 0.03$ \\
\hline \multirow{2}{*}{$\begin{array}{c}\text { CPEdl,T } \\
\left(\mathbf{s}^{\mathrm{CPEdl}, \mathrm{P} / \Omega}\right)\end{array}$} & $(4.74 \pm 0.09)$ & $(6.6 \pm 0.2)$ & $(1.02 \pm 0.04)$ & $(1.12 \pm 0.04)$ \\
\hline & x $10^{-5}$ & X $10^{-5}$ & x $10^{-4}$ & x $10^{-4}$ \\
\hline $\begin{array}{c}\text { CPEdl,P (Phase } \\
\text { Constant) }\end{array}$ & $0.744 \pm 0.002$ & $0.736 \pm 0.004$ & $0.706 \pm 0.004$ & $0.688 \pm 0.004$ \\
\hline $\mathbf{R}_{\mathrm{ct}}(\boldsymbol{\Omega})$ & $865 \pm 7$ & $189 \pm 2$ & $46.6 \pm 0.3$ & $22.4 \pm 0.1$ \\
\hline $\begin{array}{c}\text { CPEW,T } \\
\left(\mathrm{s}^{\mathrm{CPEW}, \mathrm{P} / \Omega}\right)\end{array}$ & $0.026 \pm 0.006$ & $0.032 \pm 0.002$ & $0.0371 \pm 0.0007$ & $0.0380 \pm 0.0003$ \\
\hline $\begin{array}{c}\text { CPEw,P (Phase } \\
\text { Constant) }\end{array}$ & $1.0 \pm 0.2$ & $0.86 \pm 0.06$ & $0.85 \pm 0.01$ & $0.882 \pm 0.005$ \\
\hline$\chi^{2}$ & 0.002 & 0.003 & 0.002 & 0.0008 \\
\hline
\end{tabular}

Table S3. Model fit parameters and associated error bounds for a $1.5 \mathrm{~V}$ state of charge after desodiation.

\begin{tabular}{|c|c|c|c|c|}
\hline & $5^{\circ} \mathrm{C}$ & $20^{\circ} \mathrm{C}$ & $35^{\circ} \mathrm{C}$ & $5^{\circ} \mathrm{C}$ \\
\hline $\mathbf{R}_{\text {cell }}(\boldsymbol{\Omega})$ & $6.0 \pm 0.1$ & $4.04 \pm 0.06$ & $2.74 \pm 0.04$ & $2.70 \pm 0.03$ \\
\hline \multirow{2}{*}{$\begin{array}{c}\mathrm{CPE}_{d l, T} \\
\left(\mathrm{~s}^{\mathrm{CPEdl}, \mathrm{P}} / \boldsymbol{\Omega}\right)\end{array}$} & $(7.9 \pm 0.3)$ & $(9.9 \pm 0.4)$ & $(1.13 \pm 0.05)$ & $(8.8 \pm 0.4)$ \\
\hline & $\mathrm{x} 10^{-5}$ & $\mathrm{x} 10^{-5}$ & x $10^{-4}$ & $\mathrm{x} 10^{-5}$ \\
\hline $\begin{array}{c}\text { CPEdl,P (Phase } \\
\text { Constant) }\end{array}$ & $0.707 \pm 0.005$ & $0.700 \pm 0.005$ & $0.695 \pm 0.005$ & $0.713 \pm 0.004$ \\
\hline $\mathbf{R}_{\mathrm{ct}}(\mathbf{\Omega})$ & $550 \pm 10$ & $142 \pm 2$ & $44.3 \pm 0.5$ & $21.5 \pm 0.1$ \\
\hline \multirow{2}{*}{$\underset{\left(\mathbf{s}^{\mathrm{CPEW}, \mathbf{P} / \Omega}\right)}{\text { CPEw,T }}$} & $(1.47 \pm 0.03)$ & $(1.85 \pm 0.02)$ & $(2.29 \pm 0.02)$ & $(2.86 \pm 0.01)$ \\
\hline & x $10^{-3}$ & x $10^{-3}$ & $\times 10^{-3}$ & $\times 10^{-3}$ \\
\hline $\begin{array}{c}\text { CPEw,P (Phase } \\
\text { Constant) }\end{array}$ & $0.77 \pm 0.02$ & $0.768 \pm 0.008$ & $0.778 \pm 0.004$ & $0.789 \pm 0.002$ \\
\hline$\chi^{2}$ & 0.004 & 0.002 & 0.001 & 0.0005 \\
\hline
\end{tabular}




\section{Diffusion Coefficients for Na-Ion Diffusion in Antimony Nanocrystals}

The diffusion coefficients for sodium ion diffusion through the antimony nanocrystals can be calculated from the EIS data based upon the Warburg coefficient $\sigma$ using the following equation:

$$
D_{N a^{+}}=\frac{1}{2}\left(V_{m}(d E / d x) / A F \sigma\right)^{2}
$$

where $D_{\mathrm{Na}^{+}}$is the diffusion coefficient for Na-ions through the antimony nanocrystals, $V_{m}$ is the molar volume, $d E / d x$ is the slope of the potential versus the sodiation state, $A$ is the surface area of the electrode, $F$ is the Faraday constant, and $\sigma$ is the Warburg coefficient. ${ }^{7}$ We assume that $1 / C P E_{W, T}$ and $\sigma$ are equivalent for the purposes of the diffusion coefficient calculation, which modifies the equation as follows:

$$
D_{N a^{+}}=\frac{1}{2}\left(V_{m} C P E_{W, T}(d E / d x) / A F\right)^{2}
$$

We calculated an upper bound for the diffusion coefficient using the superficial surface area of the current collector $\left(1.77 \mathrm{~cm}^{2}\right)$ and a lower bound for the diffusion coefficient based upon the surface area of completely unaggregated spherical nanocrystals with a 40-nm diameter (98 $\mathrm{cm}^{2}$ ). (Table S4). At $1.5 \mathrm{~V}$, we used the Sb molar volume $\left(18.18 \mathrm{~cm}^{3} / \mathrm{mol}\right)$ and at $0.02 \mathrm{~V}$ we used the $\mathrm{Na}_{3} \mathrm{Sb}$ molar volume $\left(71.44 \mathrm{~cm}^{3} / \mathrm{mol}\right){ }^{2,8,9}$ In addition, we multiplied the surface areas by a factor of 3.9 for the diffusion coefficient calculations at $0.02 \mathrm{~V}$ to account for the additional surface area of $\mathrm{Na}_{3} \mathrm{Sb}$ relative to $\mathrm{Sb}^{2}$ Previously, sodium diffusion coefficients have primarily been determined for desodiation close to the $\mathrm{Na}_{3} \mathrm{Sb}$ terminal sodiation state at room temperature with values ranging from $\sim 10^{-13} \mathrm{~cm}^{2} \mathrm{~s}^{-1}$ to $\sim 10^{-9} \mathrm{~cm}^{2} \mathrm{~s}^{-1}$. 6,10,11 The most relevant study, based upon the voltage window tested, was conducted between $0.1 \mathrm{~V}$ and $0.7 \mathrm{~V}$ for an antimony thin-film using a potentiostatic intermittent titration technique (PITT). ${ }^{6}$ At $0.1 \mathrm{~V}$ (the closest reference point to our data) the diffusion coefficient was on the order of $10^{-9} \mathrm{~cm}^{2} \mathrm{~s}^{-1}$. For $20^{\circ} \mathrm{C}$ at $0.02 \mathrm{~V}$, we found a 
lower bound on the order of $10^{-7} \mathrm{~cm}^{2} \mathrm{~s}^{-1}$. However, PITT and EIS are known to provide quantitatively different results, particularly for phase-change electrodes that can lead to measured diffusion coefficients that are greater than two orders of magnitude apart. ${ }^{12-16}$ Thus, our diffusion coefficients are comparable to those previously observed for antimony. Furthermore, based upon our data, the sodium diffusion coefficients in antimony are approximately two to three orders of magnitude lower than the sodium diffusion coefficients in $\mathrm{Na}_{3} \mathrm{Sb}$, which aligns well with the previous diffusion coefficient measurements using PITT, which showed a decrease in the diffusion coefficient of approximately one order of magnitude between 0.1 and $0.7 \mathrm{~V} .{ }^{6}$ The diffusion coefficients do not vary strongly with temperature, and so are not the major driver for the temperature-based performance changes.

Table S4. Diffusion coefficients based on the EIS Warburg component.

\begin{tabular}{|c|c|c|c|c|c|}
\hline & $\begin{array}{c}\text { Surface } \\
\text { Area }\end{array}$ & $5^{\circ} \mathrm{C}$ & $20^{\circ} \mathrm{C}$ & $35^{\circ} \mathrm{C}$ & $5^{\circ} \mathrm{C}$ \\
\hline$D_{N a+}\left(\mathrm{cm}^{2} \mathrm{~s}^{-1}\right)$ & Maximum & $2 \times 10^{-7}$ & $3 \times 10^{-7}$ & $4 \times 10^{-7}$ & $2 \times 10^{-7}$ \\
\hline $\begin{array}{l}\text { 0.02 V After } \\
\text { Sodiation }\end{array}$ & Minimum & $1 \times 10^{-5}$ & $2 \times 10^{-5}$ & $2 \times 10^{-5}$ & $1 \times 10^{-5}$ \\
\hline$D_{\mathrm{Na}+}\left(\mathrm{cm}^{2} \mathrm{~s}^{-1}\right)$ & Maximum & $3 \times 10^{-10}$ & $5 \times 10^{-10}$ & $5 \times 10^{-10}$ & $6 \times 10^{-10}$ \\
\hline $\begin{array}{l}1.5 \mathrm{~V} \text { After } \\
\text { Desodiation }\end{array}$ & Minimum & $2 \times 10^{-8}$ & $3 \times 10^{-8}$ & $3 \times 10^{-8}$ & $3 \times 10^{-8}$ \\
\hline
\end{tabular}




\section{REFERENCES}

(1) Weather Underground, Seattle-Tacoma International Airport Weather History https://www.wunderground.com/history/daily/us/wa/seattle/KSEA/date/2019-4-3 (accessed Apr 3, 2019).

(2) Walter, M.; Erni, R.; Kovalenko, M. V. Inexpensive Antimony Nanocrystals and Their Composites with Red Phosphorus as High-Performance Anode Materials for Na-Ion Batteries. Sci. Rep. 2015, 5, 8418.

(3) He, M.; Kravchyk, K.; Walter, M.; Kovalenko, M. V. Monodisperse Antimony Nanocrystals for High-Rate Li-Ion and Na-Ion Battery Anodes: Nano versus Bulk. Nano Lett. 2014, 14 (3), 1255-1262.

(4) Ancheyta Juárez, J. Chemical Reaction Kinetics: Concepts, Methods, and Case Studies; John Wiley \& Sons, Inc: Hoboken, NJ, 2017.

(5) Martinez-Julian, F.; Guerrero, A.; Haro, M.; Bisquert, J.; Bresser, D.; Paillard, E.; Passerini, S.; Garcia-Belmonte, G. Probing Lithiation Kinetics of Carbon-Coated $\mathrm{ZnFe}_{2} \mathrm{O}_{4}$ Nanoparticle Battery Anodes. J. Phys. Chem. C 2014, 118 (12), 6069-6076.

(6) Baggetto, L.; Ganesh, P.; Sun, C.-N.; Meisner, R. A.; Zawodzinski, T. A.; Veith, G. M. Intrinsic Thermodynamic and Kinetic Properties of Sb Electrodes for Li-Ion and Na-Ion Batteries: Experiment and Theory. J. Mater. Chem. A 2013, 1 (27), 7985-7994.

(7) Pan, K.; Zou, F.; Canova, M.; Zhu, Y.; Kim, J.-H. Systematic Electrochemical Characterizations of $\mathrm{Si}$ and $\mathrm{SiO}$ Anodes for High-Capacity Li-Ion Batteries. J. Power Sources 2019, 413, 20-28.

(8) Schiferl, D.; Barrett, C. S. The Crystal Structure of Arsenic at 4.2, 78 and $299^{\circ}$ K. J. Appl. Cryst. 1969, 2 (1), 30-36.

(9) Brauer, G.; Zintl, E. Konstitution von Phosphiden, Arseniden, Antimoniden und Wismutiden des Lithiums, Natriums und Kaliums. Z. Phys. Chem. 1937, 37B (1), 323-352.

(10) Zhang, Y.; Xie, J.; Zhu, T.; Cao, G.; Zhao, X.; Zhang, S. Activation of Electrochemical Lithium and Sodium Storage of Nanocrystalline Antimony by Anchoring on Graphene via a Facile in Situ Solvothermal Route. J. Power Sources 2014, 247, 204-212.

(11) Wang, J.; Yang, J.; Yin, W.; Hirano, S. Carbon-Coated Graphene/Antimony Composite with a Sandwich-like Structure for Enhanced Sodium Storage. J. Mater. Chem. A 2017, 5 (39), 20623-20630.

(12) Levi, M. D.; Aurbach, D. Diffusion Coefficients of Lithium Ions during Intercalation into Graphite Derived from the Simultaneous Measurements and Modeling of Electrochemical Impedance and Potentiostatic Intermittent Titration Characteristics of Thin Graphite Electrodes. J. Phys. Chem. B 1997, 101 (23), 4641-4647.

(13) Chung, M. D.; Seo, J. H.; Zhang, X. C.; Sastry, A. M. Implementing Realistic Geometry and Measured Diffusion Coefficients into Single Particle Electrode Modeling Based on Experiments with Single $\mathrm{LiMn}_{2} \mathrm{O}_{4}$ Spinel Particles. J. Electrochem. Soc. 2011, 158 (4), A371-A378. 
(14) Shi, Q.; Hu, R.; Zeng, M.; Zhu, M. A Diffusion Kinetics Study of Li-Ion in $\mathrm{LiV}_{3} \mathrm{O}_{8}$ Thin Film Electrode. Electrochim. Acta 2010, 55 (22), 6645-6650.

(15) $\mathrm{Yu}, \mathrm{P}$. Determination of the Lithium Ion Diffusion Coefficient in Graphite. J. Electrochem. Soc. 1999, 146 (1), 8.

(16) Xie, J.; Imanishi, N.; Matsumura, T.; Hirano, A.; Takeda, Y.; Yamamoto, O. Orientation Dependence of Li-Ion Diffusion Kinetics in $\mathrm{LiCoO}_{2}$ Thin Films Prepared by RF Magnetron Sputtering. Solid State Ionics 2008, 179 (9), 362-370. 